\title{
Partidários/as de esquerda, militância e consumo de vestuário
}

Left supporters, militancy and clothing consumption 


\section{Jaqueline Ferreira Holanda de Melo ${ }^{1}$}

ORCID: https://orcid.org/0000-0001-6929-2759

\section{Marcelo Machado Martins ${ }^{2}$}

ORCID: https://orcid.org/0000-0002-5846-4559

[resumo] Este trabalho é oriundo de pesquisa de mestrado concluída (UFRPE, 2016) sobre as falas acerca de práticas de consumo de 12 pessoas filiadas a partidos políticos compreendidos como de esquerda: Partido dos Trabalhadores (PT) e Partido Socialismo e Liberdade (PSOL). As respostas foram obtidas por meio de entrevistas dirigidas em profundidade e o consumo de produtos de vestuário é o recorte aqui apresentado. Pensar no que veste o corpo, sua procedência, seus impactos e suas reverberações é uma via de expressão política refletida (DOUGLAS; ISHERWOOD, [1979] 2013). São práticas cotidianas, construções identitárias (DUBAR, 1997; 2009) e crenças comunicadas a partir do vestir, em um espaço e um tempo determinados (CAMPBELL, 2002), que podem ser sistematizadas e compreendidas a partir de olhar semiótico (GREIMAS; COURTÉS, 1979). Assim, a roupa não foi um item discutido apenas em si mesmo, mas o tema suscitou associações com narrações sobre os estilos de vida, as formas de aquisição, as ponderações sobre modos de produção, além das mais comuns referentes à marca e ao preço. Embora a filiação aos partidos proporcione, em alguma medida, reflexões sobre produção e sistema econômico, as falas revelaram que as práticas dos/as filiados/as são pautadas por suas trajetórias de vida e suas aproximações a movimentos sociais que dialogam com os partidos, mas não necessariamente são orientadas por eles. 0 ser de esquerda não foi o determinante principal, mas as linhas e entrelinhas do discurso vestido e narrado durante as entrevistas, nas quais se destacaram questões sobre o consumo de bens e produtos.

\section{[palavras-chave] Partido político. Movimento social. Roupa.}

\footnotetext{
1 Mestre em Consumo, Cotidiano e Desenvolvimento Social pela Universidade Federal Rural de Pernambuco (UFRPE). Docente no Departamento de Ciências do Consumo da Universidade Federal Rural de Pernambuco (UFRPE). E-mail: jaquelinefhm@gmail.com. Lattes: http://lattes.cnpq. br/0639256942534141.

2 Doutor em Semiótica em Linguística Geral pela USP: FFLCH (ENSL: lsh). Docente no Núcleo de Design e Comunicação e no Programa de Pós-Graduação em Consumo, Cotidiano e Desenvolvimento Social da Universidade Federal Rural de Pernambuco (UFRPE). E-mail: machadomartins@yahoo.com. br. Lattes: http://lattes.cnpq.br/9084914012461108.
} 
[abstract] This work comes from a completed master's research (UFRPE, 2016), on the statements about consumption practices of 12 people affiliated to political parties understood as left: Party Workers (PT) and Socialism and Freedom Party (PSOL). The answers were obtained through in-depth interviews and the consumption of clothing products is the focus presented here. Thinking about what the body wears, its origin, its impacts and reverberations, is a way of reflected political expression (DOUGLAS; ISHERWOOD [1979] 2013). They are everyday practices, identity constructions (DUBAR, 1997; 2009) and beliefs communicated from dress, in a specific space and time (CAMPBELL, 2002), which can be systematized and understood from a semiotic perspective (GREIMAS; COURTÉS, 1979) . Thus, clothing was not only an item discussed in itself, but the theme raised associations with narrations about lifestyles, forms of acquisition, considerations about modes of production, in addition to the most common ones regarding the brand and price. Although membership of the parties provides, to some extent, reflections on production and the economic system; the statements revealed that the practices of the members are guided by their life trajectories and their approach to social movements that dialogue with the parties, but are not necessarily guided by them. The being on the left was not the main determinant, but the lines and lines of the discourse worn and narrated during the interviews in which questions about the consumption of goods and products were highlighted.

[keywords] Political party. Social movement. Clothes.

Recebido em: 06-06-2020

Aprovado em: 01-12-2020 


\section{Introdução}

Este trabalho versa sobre vivência político-partidária, consumo e identidade, com o foco no consumo de moda-vestuário. É oriundo de pesquisa de mestrado concluída (UFRPE, 2016) sobre as falas acerca de práticas de consumo de 12 pessoas filiadas a partidos políticos de esquerda (DUVERGER, [1951] 1970, BOBBIO, 1995; BRENNER, 2011): Partido dos Trabalhadores (PT) e Partido Socialismo e Liberdade (PSOL). Os/as entrevistados/as foram identificados por nomes fictícios que os/as mesmos/as escolheram junto do partido e o tempo de filiação que tinham à época da realização da pesquisa. As respostas foram obtidas por meio de entrevistas dirigidas em profundidade, que variaram de 20 a 40 minutos, no período de novembro de 2015 a janeiro de 2016. 0 trabalho se refere a práticas cotidianas, construções identitárias (DUBAR, 1997; 2009) e crenças comunicadas a partir do vestir, em um espaço e um tempo determinados (CAMPBELL, 2002), que podem ser sistematizadas e compreendidas a partir de olhar semiótico (GREIMAS; COURTÉS, 1979).

Na pesquisa desenvolvida, o partido foi considerado como a representação de um lugar de adesão, filiação do sujeito, ou seja, o estudo voltou-se às narrações de associados/ as sobre suas trajetórias de filiação e suas vivências cotidianas e não aos partidos especificamente, seja em relação à totalidade de seus programas ou ao funcionamento da instituição.

Vale destacar, porém, que os partidos políticos representam interesses e grupos, e as ideias, as reivindicações, as visões de mundo, os projetos de sociedade, etc. deles. Os conceitos que os partidos criam sobre suas perspectivas foram reunidos, histórica e, ainda, atualmente de modo genérico, sob duas grandes marcas ou proposições ou posicionamentos: direita e esquerda.

0 início da história é conhecido. Em 1789, na França revolucionária, quando os Estados Gerais, compostos por três corpos - os nobres, o clero e os "comuns", o Terceiro Estado - se autotransformou em Assembleia Constituinte, operou-se de forma espontânea uma redisposição no recinto do plenário, agrupando-se os representantes de acordo com suas posições políticas nas alas opostas da sala. Segundo relatos, a divisão espacial teria ocorrido pela primeira vez por razões de expediente - para facilitar a contagem de votos na decisão sobre o direito de veto do rei, o presidente da sessão pediu que os favoráveis à proposta se postassem à direita, os contrários a ela no outro lado. (CRUZ, 2015, p. 15)

Noberto Bobbio (1995) foi um dos principais autores a discutir a existência e a manutenção dessa díade na contemporaneidade, sendo, portanto, um autor-chave para estabelecermos, ainda hoje, nas primeiras décadas do século XXI, compreensões mínimas sobre as caracterizações concernentes às marcações direita e esquerda, bem como a dificuldade em abordá-las. No Brasil, há produção acadêmica voltada para momentos históricos, que permite pensar a díade contextualizada diante dos anos 2000. Tais reflexões são necessárias, tendo em vista que os elementos que diferenciam e constituem a díade são marcas que podem identificar, ainda hoje, idealizações e práticas realizadas por filiados a partidos políticos. 
Há de se ressalvar que Noberto Bobbio (1995) pontua a posição intermediária da díade direita vs. esquerda tendo como base uma pressuposição lógica. Nesse aspecto, seu pensamento discretizante se aproxima da estrutura elementar da significação apresentada por Algirdas J. Greimas e Joseph Courtés (1979) no denominado quadrado semiótico, retomado na sequência a partir do eixo semântico $P$ (partido de) vs. nãoP (não partido de), que se estrutura alicerçado nas oposições direta e esquerda, das quais se apreendem, por pressuposição lógica, como Bobbio (1995) fez, outras variações de sentido (figura 1), como não-esquerda e não-direita.

Bobbio (1995) ilustra a variação escalar que pode existir entre direita e esquerda e ainda nos faz refletir sobre a existência de um centro,

entre o branco e o preto pode existir o cinza; entre o dia e a noite existe o crepúsculo. Mas o cinza não elimina a diferença entre o preto e o branco, nem o crepúsculo elimina a diferença entre o dia e a noite. 0 próprio centro, ao se definir nem como direita nem como esquerda e não podendo se definir de outro modo, pressupõe a antítese e extrai da existência dela a sua própria razão de existir. (BOBBIO, 1995, p. 36)

Na prática, outras denominações como centro-esquerda ou centro-direita também podem ser apreendidas no quadrado semiótico apresentado (não-direita + esquerda e não-esquerda + direita, respectivamente). Bobbio (1995) desenvolve ainda outras díades que nos ajudam a pensar as variações entre direita e esquerda. De acordo com o autor, todos os polos e suas variações referem-se a valores, a práticas e a reivindicações que caracterizam aspectos que ora distinguem, ora assemelham, as posições distintas.

\section{FIGURA 1 - REPRESENTAÇÃO DOS CAMINHOS DA DÍADE DIREITA-ESQUERDA PROPOSTOS POR BOBBIO E ESQUEMATIZADO A PARTIR DO QUADRADO SEMIÓTICO DE GREIMAS E COURTÉS}
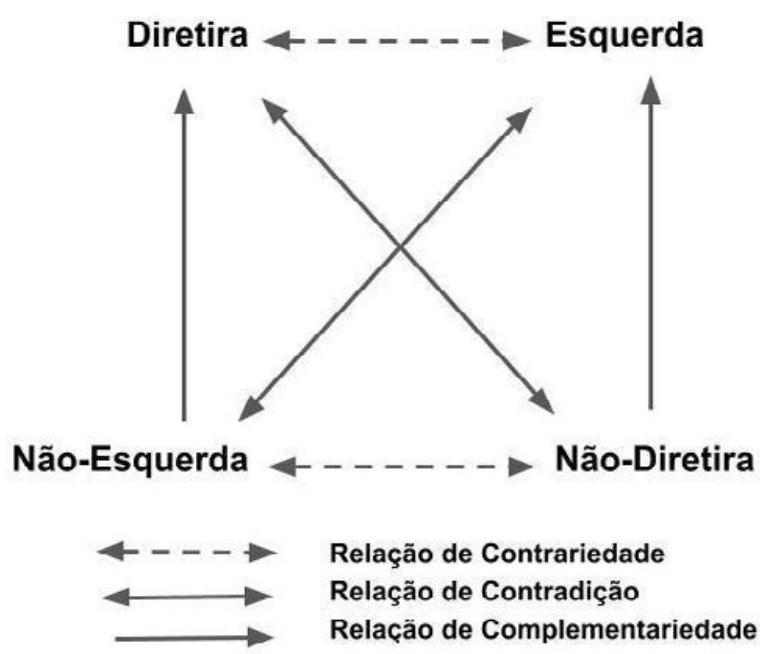

FONTE: Esquematização desenvolvida pelos autores a partir dos trabalhos de Greimas; Courtés; 1970; Fiorin, 1990. 
A título de exemplificação, o autor apresenta configurações identitárias, como: a) progressistas e conservadores - no sentido de valores, como o empoderamento das mulheres, o respeito à homossexualidade, a valorização do movimento negro; b) extremistas e moderados, principalmente no uso da violência e da força em relação a definições (anti) democráticas; c) negativo e positivo - axiologias que são atribuídas segundo as vigências valorativas sociais de uma época. Assim, podem existir esquerdas progressistas ou conservadoras e, da mesma forma, direitas, que, por sua vez, ainda são consideradas extremistas ou moderadas. Além disso, Bobbio afirma que as marcas "direita e esquerda são usadas para designar diferença no pensar e no agir políticos" (BOBBIO, 1995, p. 73).

Ademais, com base em autores/as como Dino Cofrancesco (1990) e Elisabetta Galeotti (1987), Bobbio (1995) afirma a importância de compreender a díade como marcas historicamente relativas e não como algo imutável e absoluto; sendo necessário considerar, portanto, os contextos que a englobam. Assim, é possível perceber sua aplicabilidade também a uma representação abstrata, sobretudo no que concerne à ideia espacial e escalar e, inclusive, gradual, que marca dois pontos de direcionamentos opostos ou a sua intensidade. No Brasil, de acordo com Sávio Cavalcante (2015), o ciclo político dos governos do PT constitui-se como um cenário controverso. Há uma polêmica entre aqueles que os avaliam, fundamentando-se principalmente em duas correntes:

A primeira enfatiza o quadro macroeconômico que denota a preservação do modelo neoliberal herdado da década de 1990, em que se destaca a prioridade ao capital bancário-financeiro, e vê a relativa melhora em aspectos sociais como resultado de políticas compensatórias ajustadas a esse modelo. Tratar-se-ia, nesse sentido, de um social-liberalismo. A segunda tendência enfatiza as descontinuidades com o modelo neoliberal e identifica um novo desenvolvimentismo como o traço característico desse ciclo, pois, ao reorientar a ação do Estado no âmbito das políticas de investimento, de crédito e social, teria ocorrido uma inversão da lógica neoliberal anterior. (CAVALCANTE, 2015, p. 181)

Rosa Marques e Áquilas Mendes (2006) nos fazem refletir sobre o fato de que há diferenças entre partido e governo, principalmente no caso do PT, que é formado massivamente por membros da classe trabalhadora, mas o governo que encaminhou foi de caráter burguês. Em relação a esses aspectos, André Kaysel (2015) caracterizou que o governo do PT representava um deslocamento do partido da esquerda ao centro do espectro político, ressalvando que "a direita no Brasil contemporâneo não se encontra apenas na oposição, mas também no Governo" (KAYSEL, 2015, p. 70).

Apesar do cenário de uma continuidade do neoliberalismo, é importante também registrar elementos próximos da segunda corrente que avalia os governos petistas. Embora Sávio Cavalcante afirme que "politicamente o Governo do PT não criou alternativas à situação com que deparou ao assumir o país" (CAVALCANTE, 2015, p. 183), ressalta que a partir da adoção de "políticas sociais e de cotas", o Governo mudou em alguns pontos o cenário das relações entre classes. No caso de sua análise sobre as ligações que se estabeleceram entre a classe média e as populares, o autor ressalva que os governos do PT proporcionaram o aumento da 
renda, que representaram "novas feições da classe trabalhadora proletária" (CAVALCANTE, 2015, p. 177). Apreendem-se, dessas argumentações, dois simulacros, duas imagens de governabilidade e de partidarismo com as quais as instituições do poder se apresentam e/ou são vistas por si mesmas e pelo outro: uma direita alinhada à classe média burguesa e ao consumo exacerbado e de luxo e uma esquerda alinhada à classe trabalhadora e ao consumo comedido.

Ainda de acordo com o autor, entre as medidas positivas ocorridas durante os governos do PT, há a regulamentação do trabalho doméstico assalariado, em que, por exemplo, as chamadas crias de casa, no dizer popular, tendem a diminuir; o aumento de diplomados das classes populares graças a programas como o Reuni, o Prouni e o Fies se firma; e a elevação da taxa de consumo das classes populares se configurou por causa "[das] políticas de oferta de crédito, ampliadas desde o primeiro mandato de Lula, [que] tiveram também efeito importante ao destravarem um potencial de consumo popular represado" (CAVALCANTE, 2015, p. 185).

Sobre esse último ponto, referente ao consumo, é importante registrar que, de acordo com Cavalcante (2015), houve um aumento das críticas das classes mais abastadas em relação às práticas de consumo das camadas populares. A obra Esquerda caviar, de Rodrigo Constantino (2013), materializou uma postura semelhante de moralização do consumo do outro, no caso, que fosse integrante de movimentos à esquerda. É importante destacar, pois, que tais críticas curiosamente vêm das camadas que sempre consumiram bens e serviços considerados de luxo.

Em relação à categoria consumo, delimitamos que, neste trabalho, ela é vista como um fenômeno que se constitui a partir de uma atividade sociocultural, intrínseca à existência humana, que pode refletir até mesmo vivências cidadãs e políticas sustentadas pela troca (de bens materiais ou imateriais).

Com efeito, é válido conjecturar que, pelos rumos traçados na pesquisa realizada, até mesmo expressões políticas e cidadãs convencionalmente apreendidas de ações empreendidas na esfera pública podem também representar rebatimentos na esfera privada, dado que Ana Brenner (2011) registra em suas discussões sobre militância de jovens vinculados a partidos políticos de esquerda, considerando que "o engajamento militante é, em geral, associado a hábitos de consumo mais conscientes e responsáveis, conscientes no sentido de refletir sobre suas necessidades de consumo e responsáveis no que se refere à origem e ao modo de produção dos produtos" (BRENNER, 2011, p. 239-240). Do ponto de vista da narratividade (GREIMAS; COURTÉS, 1979), o engajamento político é uma ação conjuntiva que aporta ao sujeito transformação de estados, por exemplo, da prática de consumo exacerbado, não reflexivo, à prática de consumo responsável, na qual se investem valores relacionados à conscientização desde o início da cadeia de produção até o descarte de produtos, visando ao bem-estar do ser humano e do próprio meio ambiente - em cujas variações fundam-se os discursos do consumo consciente, do sustentável, do verde, do anticonsumo, entre outros.

Este registro reitera a ideia de que o consumo pode ser uma forma de exercício de cidadania e ação política pertinentes à esfera privada, que há de rebater, dadas as práticas adotadas pelos sujeitos, na esfera pública. Além disso, pensar as várias dimensões que o consumo pode imbricar com a cidadania não pode ser descartado. No cenário brasileiro, então, em que o consumo toma cada vez mais destaque na sociedade, vê-lo em seu caráter 
multifacetado diante das realidades que permeia é possível - e muito - a ser explorado tanto nos domínios públicos como na esfera do privado, do cotidiano e do individual.

É necessário esboçar e reiterar os desdobramentos sobre a relação entre consumo, cidadania e política no Brasil se considerarmos que ocorreram políticas mais enfáticas de transferência de renda após a chegada do Partido dos Trabalhadores (PT) à presidência do país, em 2003. A efetivação de tais políticas representou uma interferência do público (diretrizes políticas) no privado (famílias). Cabe frisar que tais políticas impactaram mais grupamentos familiares oriundos de classes populares, principalmente as menos favorecidas, em sua participação na esfera pública, atendida pelo mercado (ROCHA, 2011).

Nesse sentido, é relevante ainda destacar o que Sônia Rocha (2011) discute e reforça em relação à importância de ações desse tipo adotadas nos governos do PT para a sociedade brasileira, pois

implementar um programa assistencial de transferência de renda implica também reconhecer que, numa economia urbana e monetizada, dispor de renda monetária é condição de cidadania e que cabe ao beneficiário da transferência de cunho assistencial decidir quanto ao uso do benefício. (ROCHA, 2011, p. 133)

Tal pensamento coaduna com uma das possibilidades de vinculação entre cidadania e consumo elaborada por Taschner (2010) em relação ao acesso ao consumo, pois tal aproximação também pode significar um acesso à cidadania, até mesmo uma via de inclusão social.

Nas sociedades contemporâneas ocidentais ou ocidentalizadas, o consumo - especialmente o de determinados itens - é um mecanismo de integração social, no sentido de que a posse de determinados produtos e o acesso a determinados serviços tornaram-se instrumentos para a construção e reforço de identidades sociais e, em decorrência, para o reconhecimento de um indivíduo como cidadão. (TASCHNER, 2010, p. 49)

A cidadania é tomada [em seu trabalho] como pertencimento a uma determinada comunidade ou nação. Mais do que isso: trata-se do reconhecimento da humanidade de um indivíduo e de sua aceitação, não apenas como membro daquela comunidade, mas como um par, um igual, um ser visível, digno de respeito. Nos estratos menos favorecidos, esse consumo pode ser pensado como de inclusão. A relação que se estabelece entre consumo e cidadania, neste caso, é de congruência e não de oposição. (TASCHNER, 2010, p. 49)

Apesar de tal vislumbramento, é necessário considerar que "o acesso ao consumo não elimina outros processos de exclusão” (TEIXEIRA; NASCIMENTO; BARROS, 2014, p. 14), até mesmo para não corrermos o risco de reduzir o cidadão ao consumidor, bem como encobrir contradições do processo de produção e distribuição, conforme chama atenção Canclini (1995), quando nos referimos ao direito de ser cidadão via consumo, pois a decisão sobre como são produzidos, distribuídos e utilizados os bens geralmente é restrita às elites. 
Diante das discussões expostas até então, é possível perceber que as práticas de consumo dos indivíduos estão enoveladas em variados pontos, entre os quais identidade e fazer político. Desse modo, reiteramos que o consumo é considerado, aqui, um dos meios para a construção de identidade.

Para a pesquisa realizada, a categoria identidade foi compreendida a partir da abordagem de Dubar (2009), que considera sua mutabilidade, a qual, ao longo do tempo, da história, pode ser modificada e constituída de várias maneiras, a depender das trajetórias dos indivíduos. Desse modo, é importante frisar o caráter mutável e construível da identidade que permeia nossas análises, pois consideramos que o indivíduo se desenvolve e se sustenta socialmente, de modo que a consolidação da sua identidade assim também se estrutura.

Após a aproximação às reflexões teóricas apresentadas, houve o contato com os/as filiados/as dos partidos, para a pesquisa, considerados de esquerda, como já dito anteriormente; procuramos apreender e compreender seus estilos de vida, bem como especificamente sobre o consumo de produtos de moda-vestuário e se haveria entre eles alguma relação com as ideias do partido a que se encontravam associados.

\section{Estilo de vida, estilo de vestir?}

Entre as falas sobre estilo de vida, é importante destacar as considerações de Silva (PT) e de João Grilo (PSOL), pois ambos relacionaram diretamente aos estilos de vida percebidos/ anunciados, suas práticas de consumo. Silva (PT) associa seu estilo de vida a um modo de vestir, que, por sua vez, poderia ser ligado a um estilo militante, que adotara por acreditar ser o mais adequado, já que lida com pessoas de classes populares, o que causaria uma espécie de identificação e empatia com esse segmento, tendo em vista que tais pessoas, segundo ela, também se vestem no mesmo estilo. Ou seja, estamos diante da possibilidade de identificação por meio de marcas e signos que, ainda que do âmbito político, são expressados no consumo.

Eu ando de ônibus porque eu não quero ter carro mesmo. Tanto eu quanto a minha esposa. 0 sistema é precário, mas é uma opção, porque eu não quero ter um custo gigantesco com um carro. Eu sou consumidor, mas não consumista. Minha esposa reclama muito das minhas roupas que são muito velhas. (INFORMAÇÃO VERBAL) JOÃO GRILO, PSOL, meses de filiação)

Meu estilo de vida é muito mais pé no chão. Meu estilo de vida é muito mais humilde, eu nunca gostei muito disso. Eu tenho ainda o mesmo estilo de militância. Andar de chinela/havaianas, de andar de calça jeans, de andar de camisetas, de camisetas temáticas. Eu tenho e mantenho esse estilo de militância mesmo. Como minha neta sempre diz: "Vó, tu sempre anda largadona". Porque, pra mim, de militância, se você tá de salto, tudo bem que você vá pra uma festa arrumadinho, mas você está todo dia de salto, maquiada, então pra mim isso não é militância. Como é que eu vou pra uma comunidade, como é que eu vou conversar com uma pessoa de baixa renda, se eu tô andando num nível acima do dela? Então, eu tenho que está de igual pra igual. Então eu preservo muito isso. (INFORMAÇÃo VERBAL) 
É válido frisar que essa associação do vestuário ao estilo de vida pode ser compreendida de acordo com a reflexão que Juliana Emerenciano (2005) apresenta, a partir de Maria Nacif (2001), sobre a relevância do vestuário na comunicação humana. De acordo com a autora,

[...] o vestuário representa tanto o processo técnico quanto um meio de integração entre os indivíduos e o grupo, dentro da cultura, como transmissão deste processo e, como posse do indivíduo, como elemento de construção da sua identidade pessoal, perante o grupo, e da identidade coletiva do grupo a que pertence. (EMERENCIANO, 2005, p. 11)

Desse modo, é importante compreender, principalmente a partir da fala de Silva (PT), o movimento de construção de identidade presente na relação do indivíduo com o grupo, de modo que o seu estilo de vestir a faria ser reconhecida e aceita pelos pares. A fala de Silva (PT) ainda revela a constatação que Ana Brenner (2011) teve ao estudar a militância de universitários em relação à percepção dos/as jovens sobre as mudanças após a filiação ao partido, que

[...] ocorre[m] fundamentada na ideia de que há uma estética militante e um determinado padrão de consumo que diferenciam pessoas engajadas das não-engajadas. Ou seja, pessoas engajadas se vestiriam de determinada forma. (BRENNER, 2011, p. 240)

Nesse sentido, tal constatação pode ser também compreendida a partir da afirmação de Mary Douglas e Baron Isherwood ([1979] 2013) sobre os usos sociais dos bens, que lhes retiram da condição de neutralidade. Desse modo, as roupas, nesse caso, também servem para representar o simulacro militante, assim como um elemento constituinte da identidade do/a filiado/a, como considerou Néstor Canclini (1995), revelada também a partir dos bens que os indivíduos possuem ou ostentam.

\section{Aquisição de produtos de vestuário}

Em relação especificamente ao vestuário, houve uma uniformidade da não preferência por marcas, embora Paulo (PT) e Lara (PSOL) tenham feito menção a elas. 0 vestir militante apareceu novamente na fala de Karlos Marx (PSOL). Referente aos locais de aquisição, há uma adesão maior ao comércio popular/alternativo, mas ainda são citadas as lojas de departamento.

Eu não tenho esse lance de marca pra se vestir. É raríssimo eu comprar roupa por marca. Mas normalmente uso calça jeans. Nos últimos seis meses, eu comprei na Riachuelo, na C\&A e, ultimamente, eu descobri uma coisa chamada bazar. É algo maravilhoso! (INFORMAÇÃO VERBAL) 
Eu não gosto de marca, eu procuro uma promoção, se tiver, eu ainda compro na Riachuelo, na C\&A, essas questões. Mas eu gosto de ir ali no mercado São José, entendeu? Essa semana assim, eu fui comprar roupa, eu dei uma circulada, calça jeans 80, 90, 120 reais. Aí eu disse "vou lá dentro". Quando eu cheguei lá duas calças pela metade do valor daqui. E da mesma, só não tinha etiqueta. (INFORMAÇÃO VERBAL)

Olha, sapato, eu gosto muito de sapato da Adidas, é uma mania que eu tenho, não sei o que é isso. Geralmente, assim, uma camisa básica, calça jeans, básico. Não sou de comprar roupa social e tal. (INFORMAÇÃO VERBAL)

Eu sou muito econômica. Eu tenho muita roupa. Mas é porque, por exemplo, o vestido do casamento do meu irmão, que foi há 20 anos, eu tenho. Eu sou muito cuidadosa com as minhas roupas, por isso que elas duram muito tempo. Aí eu tenho muita roupa por causa disso, de eu comprar uma blusa, uma saia, pra ficar diferente no final do ano. Geralmente, eu compro ou ganho roupa por época, dia das mães, dia dos namorados, final do ano. (INFORMAÇÃO VERBAL)

Agora eu só compro camisa de militante, comprei ontem do MTST; no Uruguai, eu comprei uma de Eduardo Galeano. Faz tempo que eu não compro uma roupa, que eu não saio pra comprar roupa. E eu tenho camisa do Sport. (INFORMAÇÃO VERBAL)

O nome das marcas foi, geralmente, mais vinculado ao produto em si, em relação aos seus atributos utilitários, e não necessariamente ao status que elas podem ter na sociedade. Apenas o caso de Paulo (PT) chama atenção, pelo fato de o entrevistado não saber explicar o porquê de sua predileção pela grife Adidas, o que reflete um comportamento hedônico.

Ainda referente ao que o vestuário representa, a fala de Karlos Marx (PSOL) exemplifica mais uma vez a reflexão sobre a existência de um perfil militante, como já salientamos em relação à fala de Silva (PT) ao descrever seu estilo de vida. No caso de Karlos Marx (PSOL), ele também pode ser identificado e aceito por seus pares por causa do seu vestuário, bem como revela, nesse sentido, sua atuação militante.

\section{Rejeições}

De acordo com Ana Brenner (2011), a militância no partido "amplia os espaços de circulação" e proporciona "experiências diferentes, contato com pessoas e com temas igualmente distintos", ao ponto que "não há uma especificidade partidária que defina engajamentos únicos ou múltiplos" (BRENNER, 2011, p. 203-204).

A despeito disso, não foi possível verificar distinção significativa entre os/as entrevistados/as em relação à motivação para suas práticas estarem vinculadas/condicionadas a seus partidos, pois, ao comparar as falas de Karlos Marx (PSOL) e Lara (PSOL), é possível observar que ambos agem distintamente, mesmo sendo filiados ao mesmo partido. Assim, compreende-se que suas motivações são a partir de suas referências cotidianas, ou seja, o partido não é necessariamente determinante, como apontara Ana Brenner (2011), pois é uma instituição que agrega multiplicidades. 
Tem coisas que saem nas notícias, tipo a Daslu, a Zara, algumas que têm trabalho escravo, que têm condições de trabalho na base da exploração muito acentuada, então, assim, as que são divulgadas, eu pelo menos evito. Eu compro na Adidas porque ela patrocina o Sport, e eu não posso fazer nada. Tirando isso, se não tiver associação muito clara. No mais a gente evita. (INFORMAÇÃo VERBAL).

Eu usei muito a Renner. Mas eu tô mudando, porque a Renner tá com o preço da Zara, que é uma qualidade de roupa muito melhor. Eu tô começando a olhar pras boutiques, pras outras marcas. Eu gosto muito da Zara. Sandália, de Jailson Marcos. Eu sou muito o produto, preço. Eu olho muito o preço. (INFORMAÇÃO VERBAL)

É pertinente destacar o fato de que o tempo de filiação político-partidária não pareceu fator condicionante durante as entrevistas, mas sim o envolvimento deles/delas com a militância, conforme Ana Brenner (2011) também encontrou na sua pesquisa.

O tempo maior ou menor de militância não determina, contudo, intensidade maior e menor, respectivamente, de militância. Poderíamos esperar que jovens de militância mais longa tivessem, necessariamente, um investimento ou uma militância mais intensa e que os militantes mais recentes tivessem menor investimento, mas veremos nas narrativas dos jovens que pouco tempo de militância também pode ser sinônimo de grande investimento militante. (BRENNER, 2011, p. 136)

João Grilo (PSOL) é um exemplo do que expressou a autora, pois declarou, no início de sua entrevista, que sua atuação militante (feita há anos) independeu de sua filiação (realizada poucos meses antes de quando a entrevista foi realizada), e tem rejeições, por exemplo, a certas marcas de produtos de moda-vestuário.

Ambev, Nike, essas redes Zara, M.Officer, enfim, marcas que a gente sabe que tem algum vínculo com esse tipo de precariedade no mundo do trabalho, eu não apenas evito, como isso faz parte de um aspecto da militância de tentar conversar com outras pessoas para que elas evitem também. (INFORMAÇÃO VERBAL)

Subjaz às falas analisadas uma enunciação que mobiliza argumentos para o desenvolvimento de práticas de consumo mais centradas em movimentos de militância em prol de uma causa específica, e não necessariamente no que reverbera no discurso do partido político. Em vários momentos, os enunciadores (entrevistados/as) explicitam seus processos de identificação com determinadas causas e como agem para se manterem coerentes a elas. Ao mesmo tempo, são sujeitos que sancionam positivamente, por exemplo, as roupas cuja procedência é conhecida e reconhecida euforicamente por eles/elas, e cujo uso garante um reconhecimento e uma aceitação dentro do universo no qual circulam e atuam. As considerações até então apresentadas descortinam um sentido diferente para o que se apreende no senso comum, qual seja, o sujeito que assume de fato a militância torna-se fortemente conjunto com práticas de consumo mais conscientes, enquanto, por outro lado, o sujeito ligado a um partido político não se encontra necessariamente conjunto com tais práticas. 


\section{Consumo, filiação e partido}

Em relação à mudança no consumo após a filiação político-partidária, houve uma distribuição equilibrada entre os que consideravam sua ocorrência com um "sim" ou um "não". Entre os que assumiram que ela ocorreu, a maioria das respostas se deu quanto a passar a consumir - materiais de campanhas e de estudo sobre o partido, mas também o caso de Karlos Marx (PSOL), que se refere ao consumo de alimentos orgânicos. Entre os "não" e os "não necessariamente", chamam atenção as respostas "não", de Movimento Negro (PT), e o "não necessariamente", de João Grilo (PSOL) e Cristina (PSOL), que seguem:

\footnotetext{
Não, a minha chegada no PT não me influenciou. Inclusive, quando eu cheguei tinha um debate muito interessante, muita gente com quem eu convivia não consumia Coca, por ser um produto dos Estados Unidos. Era um produto que chamava danoso aos socialistas. Mas eu consumia minha Coca sem essa prerrogativa estabelecida. (INFORMAÇÃO VERBAL)
}

O único consumo que está ligado diretamente ao partido é a compra de broche de solzinho, camisas militantes e tal... Mas o que vale mais é o aprofundamento das discussões, acho que não é o partido necessariamente. (INFORMAÇÃO VERBAL)

Não necessariamente, porque isso tem a ver com uma questão de aprofundamento, de certo conhecimento que tenha a ver com questão ideológica, que é de me preocupar se a loja tem um passado com algum tipo de prática, eu me tornei um pouco mais cuidadoso. (INFORMAÇÃO VERBAL)

A fala de Movimento Negro (PT) é bastante interessante por causa do caso emblemático do consumo da Coca-Cola por "militantes de esquerda", geralmente questionados sobre suas práticas de consumo com tons moralizantes, o que se percebe não apenas por parte das pessoas que não são da esquerda, mas ainda dos seus próprios militantes. Em contrapartida, também é importante observar as falas de Cristina (PSOL) e de João Grilo (PSOL), referentes ao fato de que alguma mudança no consumo acontece pela aproximação e pelo aprofundamento em discussões específicas, que pode estar mais relacionada a um exercício militante do que ao ato de filiação político-partidária.

Buscamos compreender como eles/as se posicionavam na condição de observador do consumo do outro - e não de observado. Assim, em relação a esse questionamento sobre sua condição de observador/a do consumo alheio, vinculada a discussões encampadas pelos partidos, Lili (PT) menciona que as decisões de consumo de cada indivíduo têm cunho pessoal, que "não é só uma questão do partido" (INFORMAÇÃO VERBAL), pois engloba várias discussões não específicas sobre consumo, mas "reflexões sobre o capital" (INFORMAÇÃO VERBAL) que a ajudaram, por exemplo, a pensar a sociedade como um todo. Por outro lado, Pétrio (PT) menciona a existência de discussões dentro do partido encaminhadas por integrantes de movimentos sociais, como o caso do movimento do campo, que sensibiliza a evitar o consumo de produtos constituídos de transgênicos. 
A participação em movimentos sociais, ou a afinidade com eles, foi um fator que também incidiu nas práticas de consumo de parte dos/as entrevistados/as; como apontado anteriormente, dado que, de acordo com os depoimentos apreendidos, foi possível perceber que o consumo aparece de modo transversal nas discussões alavancadas por esses movimentos. É importante registrar que os partidos dos/as entrevistados/as parecem guarda-chuvas, sob os quais alguns movimentos sociais estão, o que pode proporcionar uma aproximação entre eles, isto é, os próprios movimentos e os/as filiados/as aos partidos.

\section{Considerações finais}

A partir da pesquisa realizada foi possível repensar o simulacro das imagens construídas em torno das pessoas filiadas aos partidos de esquerda, e os resultados direcionaram também para uma reflexão importante acerca da ideia de que suas práticas de consumo são, ou mesmo devem ser, mais conscientes e responsáveis. Assim, por parte dos/as entrevistados/as, a composição do vestuário foi fortemente vinculada a uma estilização da representação militante, o que nos instiga a considerar uma continuidade do trabalho na tentativa de rever as idealizações referentes a um padrão de esquerda, considerando, por outro lado, a diversidade intrínseca a esse grande grupo.

Repensar esse simulacro faz-se necessário, pois, assim como nós, filiados/as à esquerda estabelecem vínculos sociais diversos, para além dos político-partidários e, embora tenham críticas por vezes severas ao sistema capitalista vigente, dele também fazem parte, nele transitam e em meio a ele constroem suas identidades.

Em síntese, percebemos que ser consciente e responsável sobre as práticas de consumo vai além do fato de estar filiado/a à uma instituição de esquerda; é algo que também concerne às particularidades de cada indivíduo, aos seus vínculos sociais diversos estabelecidos no cotidiano. Desse modo, a narratividade mudará conforme a especificidade de cada indivíduo, embora prevaleça um padrão de que a conjunção a uma determinada causa de militância resulta em estado de transformação para práticas de consumo influenciadas por ela, enquanto, no caso de estar conjunto ou disjunto de um partido não se apresentou determinante. 


\section{Referências}

BOBBIO, Norberto. Direita e esquerda: razões e significados de uma razão política. Trad. Marco Aurélio Nogueira. 2. ed. São Paulo: Editora da Universidade Estadual Paulista, 1995.

BOURDIEU, Pierre. A distinção: crítica social do julgamento. Porto Alegre: Zouk, [1979] 2013.

BRENNER, Ana Karina. Militância de jovens em partidos políticos: um estudo de caso com universitários. 2011. 309 f. Tese (Doutorado em Educação) - Faculdade de Educação da Universidade de São Paulo, São Paulo, 2011.

CAMPBELL, Colin. A ética romântica e o espírito do consumismo moderno. Rio de Janeiro: Rocco, 2002.

CANCLINI, Nestor García. Consumidores e cidadãos: conflitos multiculturais da globalização. Rio de Janeiro: Ed. UFRJ, 1995.

CAVALCANTE, Sávio. Classe média e conservadorismo liberal. In: CRUZ, Sebastião Velasco e; KAYSEL, André; CODAS, Gustavo (orgs.). Direita, volver! 0 retorno da direita e o ciclo político brasileiro. São Paulo: Editora Fundação Perseu Abramo, 2015. p. 177-196.

CONSTANTINO, Rodrigo. Esquerda caviar: a hipocrisia dos artistas e intelectuais progressistas no Brasil e no mundo. Rio de Janeiro: São Paulo: Editora Record, 2013.

CRUZ, Sebastião Velasco. Elementos de reflexão sobre o tema da direita (e esquerda) a partir do Brasil no momento atual. In: CRUZ, Sebastião Velasco e; KAYSEL, André; CODAS, Gustavo (orgs.). Direita, volver! 0 retorno da direita e o ciclo político brasileiro. São Paulo: Editora Fundação Perseu Abramo, 2015. p. 13-48.

DOUGLAS, Mary; ISHERWOOD, Baron. 0 mundo dos bens: para uma antropologia do consumo. Rio de Janeiro: UFRJ, [1979] 2013.

DOUGLAS, Mary. 0 mundo dos bens, vinte anos depois. Horizontes Antropológicos. Porto Alegre, ano 13, n. 28, jul./dez. [1999] 2007, p. 17-32.

DUBAR, Claude. A crise das identidades: a interpretação de uma mutação. Trad. Mary Amazonas Leite de Barros. São Paulo: Editora da Universidade de São Paulo, 2009, 108 p.

DUBAR, Claude. A socialização: construção das identidades sociais e profissionais. Portugal: Porto Editora, 1997, 190 p.

DUVERGER, Maurice. Os partidos políticos. Rio de Janeiro: Zahar Editores, [1951] 1970. 
EMERENCIANO, Juliana. A comunicação através das roupas: uma compreensão do design de moda além da superficialidade. Revista Design em Foco, v. 2, n. 1, jan./jun. 2005, p. 9-25.

FIORIN, José Luiz. Fundamentos teóricos para ensino da leitura. In: XIII SEMANA DE LETRAS. Santa Maria: Local onde a semana foi realizada, 1990.

GREIMAS, Algirdas Julien; COURTÉS, Joseph. Dicionário de semiótica. São Paulo: Editora Cultrix, 1979.

KAYSEL, André. Regressando ao regresso: elementos para uma genealogia das direitas brasileiras. In: CRUZ, Sebastião Velasco e; KAYSEL, André; CODAS, Gustavo (orgs.). Direita, volver! 0 retorno da direita e o ciclo político brasileiro. São Paulo: Editora Fundação Perseu Abramo, 2015. p. 49-74.

MARQUES, Rosa Maria; MENDES, Áquilas. O social no governo Lula: a construção de um novo populismo em tempos de aplicação de uma agenda neoliberal. Revista de Economia Política, v. 26, n. 1 (101), jan./mar. 2006, p. 58-74.

MILLER, Daniel. Teoria das compras: o que orienta as escolhas dos consumidores. São Paulo: Nobel, 2004b.

RICHARDSON, Roberto Jarry; PERES, José Augusto de Souza et al. Pesquisa social: métodos e técnicas. São Paulo: Atlas,1999.

ROCHA, Sônia. O programa Bolsa Família: evolução e efeitos sobre a pobreza. Economia e Sociedade, Campinas, v. 20, n. 1 (41), abr. 2011, p. 113-139.

TASCHNER, Gisela. Cultura do consumo, cidadania e movimentos sociais. São Leopoldo, Ciências Sociais Unisinos, v. 46, n. 1, jan./abr. 2010, p. 47-52.

TEIXEIRA, Juliana Cristina; NASCIMENTO, Marco César Ribeiro; BARROS, Amon. Os rolezinhos em shoppings centers: reflexões sobre o que agregam e em que desafiam os estudos de segregação social e urbana. In: VIII ENCONTRO DE ESTUDOS ORGANIZACIONAIS DA ANPAD. Gramado: Local onde o encontro foi realizado, 2014.

\section{Agradecimentos}

Ao Conselho Nacional de Desenvolvimento Científico e Tecnológico (CNPq); ao programa de Pós-Graduação em Consumo, Cotidiano e Desenvolvimento Social (PGCDS) da Universidade Federal Rural de Pernambuco; às pessoas que se dispuseram a serem entrevistadas para o desenvolvimento da pesquisa. 